\title{
Development of a Smart Grid Course in an Electrical Engineering Technology Program
}

\section{Dr. Murat Kuzlu, Old Dominion University}

Murat Kuzlu (Senior Member - IEEE) joined the Department of Engineering Technology, Old Dominion University (ODU) in 2018 as an Assistant Professor. He received his B.Sc., M.Sc., and Ph.D. degrees in Electronics and Telecommunications Engineering from Kocaeli University, Turkey, in 2001, 2004, and 2010, respectively. From 2005 to 2006, he worked as a Global Network Product Support Engineer at Nortel Networks, Turkey. In 2006, he joined the Energy Institute of TUBITAK-MAM (Scientific and Technological Research Council of Turkey - The Marmara Research Center), where he worked as a senior researcher. Before joining ODU, he worked as a Research Assistant Professor at Virginia Tech's Advanced Research Institute. His research interests include smart grid, demand response, smart metering systems (AMR, AMI, AMM), home and building energy management systems, co-simulation, wireless communication, and embedded systems.

\section{Dr. Otilia Popescu, Old Dominion University}

Dr. Otilia Popescu received the Engineering Diploma and M.S. degree from the Polytechnic Institute of Bucharest, Romania, and the PhD degree from Rutgers University, all in Electrical and Computer Engineering. Her research interests are in the general areas of communication systems, control theory, signal processing and engineering education. She is currently an Associate Professor in the Department of Engineering Technology, at Old Dominion University in Norfolk, Virginia, and serves as the Program Director for the Electrical Engineering Technology Program. In the past she has worked for the University of Texas at Dallas, University of Texas at San Antonio, Rutgers University, and Politehnica University of Bucharest. She is a senior member of the IEEE, served as associate editor for IEEE Communication Letters, and has served in the technical program committee for the IEEE ICC, WCNC, RWW, VTC, GLOBECOM, and CAMAD conferences.

\section{Dr. Vukica M. Jovanovic, Old Dominion University}

Dr. Vukica Jovanovic is a Batten Fellow and an Associate Professor of Engineering Technology in Mechanical Engineering Technology Program. She holds a Ph.D. from Purdue University in Mechanical Engineering Technology, focuses on Digital Manufacturing, Magistar (Ph.D. candidate) degree in Indsutrial Engineering and Management, focused on Production Systems Design, and dipl.ing. degree in Industrial Engineering focused on Mechatronics, Robotics and Automation. She went through engineering pathways herself, completing master electrician degree when completing Technical School in Uzice, Serbia, focusing on pre-engineering program on high power voltage systems and maintenance of electromechanical systems. Her research is focuses on engineering pathways, career and technical education, digital thread, cyber physical systems, mechatronics, digital manufacturing, broadening participation, and engineering education. She is a Director of Mechatronics and Digital Manufacturing Lab at ODU and a lead of Area of Specialization Mechatronics Systems Design. She worked as a Visiting Researcher at Commonwealth Center for Advanced Manufacturing in Disputanta, VA on projects focusing on digital thread and cyber security of manufacturing systems. She has funded research in broadening participation efforts of underrepresented students in STEM funded by U.S. Department of Education, focusing on computer science and cybersecurity pathways, and from Office of Naval Research, focusing on mechatronic pathways. She is part of the ONR projects related to the additive manufacturing training of active military. She is also part of the research team that has multiple projects funded from NSF focusing on veteran pathways and their success in engineering. She leads the team that delivers the summer program to nine graders that focus on broadening participation of underrepresented students into STEM (ODU BLAST), funded by the Virginia Space Grant Consortium. 


\section{Development of a Smart Grid Course in an Engineering Technology Program}

Electric power systems courses have been traditionally offered by electrical engineering technology programs for a long time, with the main objective to introduce students to the fundamental concepts in the field of electric power systems and electrical to mechanical energy conversion. A typical electric power systems course covers a variety of topics, such as general aspects of electric power system design, electric generators, components of transmission and distribution systems, power flow analysis, system operation, and performance measures. In the last decades, electric power systems have significantly modernized alongside with requirement of improvement in system efficiency, reliability, cybersecurity, and environmental sustainability. The current modernized grid is called "Smart Grid," which integrates advanced sensing technologies, control methods using machine learning approaches, and integrated communications into current electric power systems. Consequently, offered electric power systems courses are required to update in electrical engineering technology as well, to meet the industry needs of a workforce prepared to integrate smart grid technologies, such as advanced sensing, control, monitoring, communication, renewable energy, storage, computing, cybersecurity, etc. However, such updates of the course content are not always easy to implement due to the complexity of smart grid technologies and the limited number of instructors having knowledge of those technologies. In addition, smart grid courses should include a hands-on component aligned with the theoretical upgrades introduced in the course in the form of term projects. Such projects can be on a variety of topics, such as smart home/building, smart meter, smart distribution system, microgrid, communication infrastructure, Distributed energy resources (DERs) (e.g., rooftop solar photovoltaics (PV), wind), electric vehicle (EV), customer engagement, energy generation forecasting, load forecasting, and others. This paper will discuss the details of introducing a new course on smart grids in an electrical engineering technology program, including detailed examples of project selection.

\section{Introduction}

Power systems is a core field of electrical engineering technology. Electrical engineering technology has always been one of the largest programs in undergraduate engineering technology in terms of enrollment [1]. Programs focused specifically on power engineering in the U.S. are rising recently due to the trends in renewable energy, always changing gas prices, and aging power engineering workforce and it is well known that there is a shortage of welltrained and well-educated engineers in the area of Electric Power Systems, Machines, and Energy for quite some time [2]. Due to the changes in the number of credit hours related to the ABET requirements, the number of technical courses was reduced from 140 credits to 120 , and many programs replaced power engineering hands-on labs and courses with some other electrical engineering and electrical engineering technology courses to follow the trends in the technology development [2]. Mostly, power courses will be limited to the senior electives with a limited laboratory component, and the number of students enrolled kept on dropping due to the lower 
pay in this specific industry than some other industries that hire electrical students [2]. However, these trends are changing due to the development of smart infrastructures.

The main objective of power system engineering is to introduce students to the fundamental concepts in the field of electric power systems, which focuses on the generation, transmission, distribution, and utilization of electric power and the electrical equipment and systems, such as generators, motors, transformers and remote terminal units, a variety of sensors, power flow analysis, system operation, and performance measures, as well as supervisory control and data acquisition (SCADA) [3]. Traditionally, power system engineers are responsible for managing and maintaining the electric power grid consisting of the three main subsystems, namely generation, transmission, and distribution. Generation of electricity is the process of producing electricity from various kinds of energy, such as flowing water, solar radiation, wind, hydro plants, chemical combustion, and nuclear fission. The bulk generation system is connected to the distribution system via the transmission system carrying electricity long distances. The distribution domain is electrically connected between the transmission domain and the customer domain at the metering points for consumption [4].

Electrical Engineering Technology programs have offered electric power systems courses based on this core framework for a long time. According to the ABET, there are 125 institutions in the United States of America with B.S. degrees offered to the students that are accredited under the Institute of Electrical and Electronics Engineers (IEEE) professional society support and under The Engineering Technology Accreditation Commission (ETAC) umbrella [5]. There is no specific program that only focuses on power engineering technology, and the courses are usually embedded into the existing curriculum.

In recent years, the power systems industry is undergoing major changes 6]. It has significantly modernized alongside the requirement of improvement in system efficiency, reliability, security, and environmental sustainability. The modernized grid is called "Smart Grid," which integrates advanced sensing technologies, renewable energy sources, control methods using machine learning approaches, communications into current electric power systems [7]. The most common career paths for power engineers are showing how some of these new trends in power technologies are leading to new occupations such as Data Scientists that are now required in power engineering since it is such a data-driven industry [8]. The reported salary for power engineers $(\$ 80,737 /$ year $)$ is higher than the average reported salary for electrical engineering technologists (\$64,754/ year) [9]. An entry-level Power Engineer with less than 1year experience can expect to earn an average total compensation of $\$ 69,733$ based on 18 salaries reported on PayScale.com, while an entry-level Electrical Engineering Technologist with less than 1-year experience can expect to earn an average total compensation of $\$ 53,595$ based on 28 salaries [9]. Therefore, offered electric power systems courses are required to update in electrical engineering technology curricula to be able to prepare the future power systems engineers based on the needs of the power industry [10]. 
The updated curriculum should cover advanced information and communication technologies along with smart grid technologies, such as advanced sensing, control, monitoring, communication, renewable energy, storage, load, and energy generation forecasting, and cybersecurity. Those courses should immediately address industry needs in the short term, i.e., the next five-to-ten years, to meet the future electric power workforce [11]. In addition, the evolution of power system engineering programs and curriculum should be performed collaboratively with industry stakeholders. In the literature, a variety of studies have been conducted, which address those issues in the traditional electric power systems engineering education and propose smart grid education models for modern electric power system engineering curriculum.

Smart grid courses should cover projects that are aligned with the theoretical underpinnings introduced in the course and should also embed a project-based learning approach [12]. According to the study [13], a smart grid education module should include the emerging smart grid technologies, such as energy storage technologies, advanced power electronics, control systems, automation, renewable energy systems integration, system optimization, realtime control, and other related topics as well as to meet the challenges ahead in the electric power sector. Authors in [14] discussed power systems engineering in terms of curriculum, supply, and demand for education, faculty careers, and alternative strategies and emphasized the importance of power engineering education in the power engineering profession.

A hands-on laboratory course is also crucial, along with a lecture-based course in power systems engineering, as this delivery mode will better help the students to understand the smart grid concepts. However, current curricula mostly include traditional topics for laboratory courses, such as electric power and machinery. The laboratory courses should also update along with the updated lecture courses and cover smart grid technologies, i.e., renewable and green energy integration, energy efficiency, energy storage. Authors in [15] propose a hands-on laboratory course consisting of three major components, (1) Power System Simulations performing on a miniature real-world power system, (2) Computer Simulations including widely used software tools by power utilities and high voltage, and (3) High Voltage performing the High Voltage use cases.

This paper discusses a newly developed smart grid course focused on smart grid technologies and project assignments in an Electrical Engineering Technology Program. The smart grid technologies covered in the course include renewable energy systems and grid integration, smart distribution system, microgrid, communication infrastructure, energy storage, electric vehicle (EV), as well as energy generation and load forecasting. The objective of the project assignment is the design and analysis of a smart grid technology or its application in a system through software or simulation tools. 


\section{The Smart Grid Course as part of the Electrical Engineering Technology Curriculum}

Until recently, the Electrical Engineering Technology (EET) program at Old Dominion University has followed the traditional specializations in any electrical and computer engineering program, with a concentration in computer engineering technology and one in electrical systems technology. Through a variety of upper-level courses in advanced electronics, communication systems, power systems, or programmable logic controllers, students were able to focus their studies in specific areas of electrical engineering, which is a practice followed very often by engineering programs. Starting with fall 2018, based on discussions with the industrial advisory board and in response to the trends in the job market, the EET program decided to expand the electrical system concentration into four separate concentrations, aligned with the specialized courses offered in the program $[12,13]$. These areas of concentration were Communication Systems, Embedded Systems, Mechatronics Systems, and Power Systems. In support of the introduction of these new concentrations, some of the existing courses were updated, and new courses were also added. On each concentration, students are required to take some courses specific to the concentration, and they are still to choose two senior elective courses, which may be either within the same area or they may be out of their specialization area, with the goal of broadening their background. For the Power System concentration, students are required to take core courses in DC and AC circuits, electronic devices and circuits, digital and linear electronics, microprocessors, and programming, and specific to their concentration, they also take some required courses in power systems and machinery, electrical power transmission and distribution and alternative energies. Under the new curriculum structure, as an upgrade on the power systems concentration, a new course on smart grids was introduced. This course is offered as an elective course and can be taken by the students on the power concertation to add to their field of specialization, or by students on other concentrations to broader their experience. In the updated version of the EET curriculum, the EET minor was also revised to introduce more course options, and the newly developed Introduction to Smart Grids course is currently one of the possible minor course choices. In addition to the EET program, the new smart grids course was also added as an option for the interdisciplinary minor of Energy Engineering offered by the College of Engineering.

While the updated curriculum with new concentrations and newly developed courses is still in transition, with a large group of students still on the old model, students appreciate the more specialized choices for concentrations. This was noted in student opinion surveys, students exit surveys, and through advising talks, when students get the chance to express their interests and choices, and when very often is noted that students on the old model are asking if it is possible for them to transition on the new curriculum model. Also, after offering the new Introduction to Smart Grids course twice so far, increased interest in the course is noted among the students, along with a very positive response from the student side. 


\section{Smart Grid Course Description, Objectives, and Content}

The smart grid course is offered as a 400-level course, "Introduction to Smart Grids," at the Electrical Engineering Technology (EET) program of Old Dominion University since Fall 2019. This smart grid course introduces the students to the fundamental principles and techniques in smart grids, with a focus on information and communication technologies (ICT) deployed to modernize the electric energy infrastructure and systems. It provides students an overview of the smart grid and its main components, smart devices at generation, transmission, distribution, and customer levels. The course also discusses distributed energy resources (DER) and emerging technologies, i.e., solar PV, microturbines, wind turbines, fuel cells, biomass generators, electric storage, electric vehicles (EV) and chargers, advanced metering infrastructures as well as customer systems, including demand response, home energy management and smart appliances in the smart grid environment. Advanced information and communications technologies are discussed, along with standards and protocols in the smart environment. Real-world smart grid projects are presented from several categories, such as electric distribution systems, electric distribution systems, advanced metering infrastructure, and customer systems.

This course is designed for senior undergraduate students, and it only requires a prerequisite course covering the fundamental of electric power and machinery. Basic knowledge of power systems and computer and communications networks, as well as some background in calculus and linear algebra, will also be helpful, but the concepts needed are reviewed in the course. For this course, no book is required, but a list of references is provided, and that handouts based on these references are provided along with selected journal and conference papers. The students need to read those selected papers from several journals and conferences, i.e., IEEE Transactions on Smart Grid, IET Generation, Transmission \& Distribution, IEEE Power \& Energy Society Innovative Smart Grid Technologies Conference, and IEEE Power \& Energy Society General Meeting Conference.

Having successfully completed this course, the student will be able to:

- Understand what the smart grid is and its components

- Understand emerging technologies in the electric power distribution

- Understand operating principles and smart grid applications in power distribution systems

- Analyze potential impacts of emerging technologies on distribution network operation

- Understand the concept of home energy management and demand response

- Understand different communication technologies and standards for smart distribution and customer operation

- Analyze selected smart distribution and customer system projects

For course assessment and grading, the following instruments are used: two in-class tests and a final exam, random quizzes, and a term project. For the term project, students are required to prepare two drafts during the semester and a final report. The term project concludes with a final presentation. Traditional power systems courses focus on the fundamental power systems 
component with a limited content of the emerging technologies, such as distributed energy resources, advanced data communication, big data, transactive control, electric vehicle, smart buildings, blockchain-based energy trading, cybersecurity, etc.

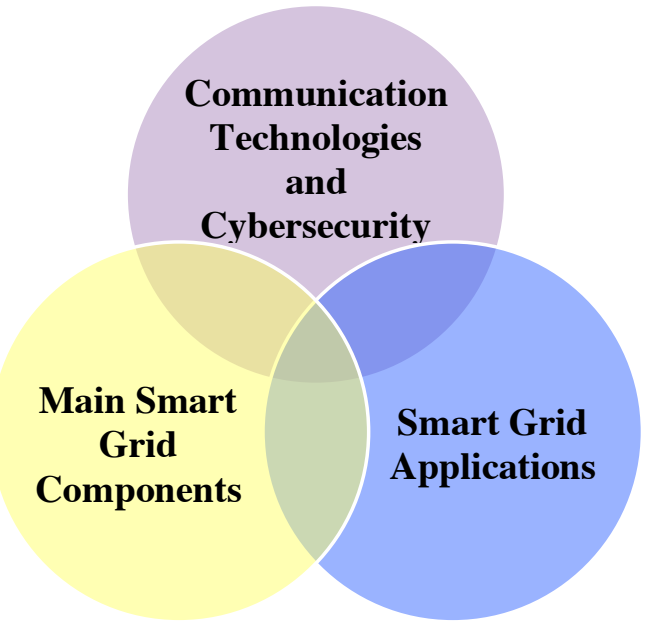

To complement the material covered in the lectures, a term project is assigned in the course, for which students are required to design and analyze a smart grid technology or its applications. The course content can be broken into three categories: (1) Main Smart Grid Components, (2) Communication Technologies and Cybersecurity, and (3) Smart Grid Applications, as shown in Figure 1.

Figure 1: Course content categories

The first category of the course provides an overview of the smart grid and its main components. Characteristics of the smart grid with its key areas are defined in this category. In addition, the main smart grid components are explained at generation, transmission, distribution, and customer levels. In support of this category, the course includes the following lectures and related topics:

- Introduction to smart grids: Smart grid definition and key areas, characteristics of the smart grid, and smart grid conceptual model.

- Generation: Conventional power plants, distributed energy resources (DERs), storage technologies.

- Transmission: Interconnections, Independent System Operator (ISO), Regional Transmission Organization (RTO), Phasor measurement unit (PMU), stability issues of power systems.

- Distribution: Smart grid components and applications in the distribution domain, renewable energy integration, substations, automated meter reading (AMR), advanced metering infrastructure (AMI).

- Customer: Smart grid components and applications in the customer domain, smart appliances, electric vehicles (EVs), and charging stations.

The second category of the course introduces the information and communication technologies along with smart standards and protocols widely used in smart grid applications. The objective of this category is to provide an overview of Communication technologies for the smart grid and network requirements for major smart grid applications as well as smart grid cybersecurity and standards/protocols related to substations, distribution, and AMI, home area network, building energy management, and distributed energy sources. This category is covered in the course by the following lectures with related topics: 
- Smart Grid Communications: Smart grid network architecture, wired and wireless communication technologies for the smart grid, network requirements for major smart grid applications, real-world examples, and simulation studies.

- Smart Grid Security: Classification of cyber-attacks, and possible cyber-attack scenarios in the smart grid environment, privacy concerns, security concerns in smart buildings, security standards guidelines.

The third category of the course covers specific smart grid applications at transmission, distribution, and customer levels. It also includes examples from real-world smart grid projects, including technologies implemented, project status, recorded benefits, and lessons learned. In this category, the impact of distributed degeneration on distribution network operations is also involved in terms of voltage profiles, power losses, power flow direction, short circuit levels, and system reliability. The widely used system reliability indices, including System Average Interruption Frequency Index (SAIFI), System Average Interruption Duration Index (SAIDI), Customer Average Interruption Duration Index (CAIDI), Average System Availability Index (ASAI), and Energy Not Supplied (ENS), are investigated with several case studies. This category includes the following lectures with related topics:

- Smart Grid Applications at Transmission Domain: Wide area monitoring and control systems.

- Smart Grid Applications at Distribution Domain: Smart metering, smart distribution transformer, conservation voltage reduction (CVR), demand response, transactive control, blockchain, distribution automation.

- Smart Grid Applications at Customer Domain: Home energy management systems, smart plugs, smart homes, smart buildings.

- Smart Grid Projects: Electric transmission systems, electric distribution systems, customer systems projects.

- Impact Of Distributed Generation On Distribution Network Operations: Impacts on voltage profiles, power losses, power flow, short circuit levels, and system reliability.

In fall 2020, when it was offered for the second time, the course included some more updates with a focus on artificial intelligence and machine learning methods and how to apply them to load and energy generation forecasting and anomaly detection cases in smart grid applications. It was planned on running several hands-on activities in the class that introduces simple artificial intelligence and machine learning models to students through load and energy generation forecasting and anomaly detection cases widely used in the smart grid environment. Due to the COVID-19 pandemic, in fall 2020, the course was offered in online synchronous mode, and the hands-on activities had to be run remotely.

\section{Term Projects}

The purpose of this assignment is to design and analysis of a smart grid technology as well as its application in a system, such as smart home/building, smart meter, smart distribution system, microgrid, communication infrastructure, distributed energy resources (e.g., the status of rooftop PV, solar/wind penetration), electric vehicle (EV), customer engagement, smart cities, energy generation forecasting, load forecasting, and others. In addition, it is expected to use a 
software/tool (Python, C/C++, Matlab/Simulink, eQuest, Energy+, GridLab-D, NetSim, etc.) on the project. Students select one topic related to the smart grid and work individually to complete this assignment. They should complete two reports, a two-page project proposal, and a research paper. The semester ended with presentations of the term projects. Two options were given to students for the term-project assignment, including (1) Hardware and/or software development for the selected smart grid application, (2) Writing a term paper related to smart grids. Most students preferred to write a research paper on smart grids. Most term projects are related to renewable energy generation and smart systems.

Project Examples are:

- Modeling A Photovoltaic Generation System Using Simulink,

- Smart Homes and Buildings,

- International Space Station Smart Energy Storage,

- Geothermal Energy (Geyser),

- Thermoelectric Generators Applied to The Solar Arrays,

- Turbo Charged Nuclear Power Plant,

- Energy Storage and Load Simulation,

The project assignment is crucial in engineering technology education, which can help students as future engineers make better decisions in technical work as well as to understand the theory through real-world experience. This assignment also helped them to run and manage each component in a project in terms of tasks, schedule, scope, and budget. Many of the students appreciate the project assignment. They shared their experience and gaining knowledge on the smart grid concept and emerging technologies in the smart grid environment through the project assignment.

\section{Student Feed Back and Lessons Learned}

"Introduction to Smart Grids" course was offered for the first time to the senior undergraduate students at Electrical Engineering Technology of Old Dominion University in fall 2019, as a pilot course, and then in fall 2020. The smart grid concept is new and challenging for students in terms of the content and the concept. However, students are highly motivated to learn emerging technologies, especially renewable energy, electric vehicles, and energy storage technologies, and discussing the next-generation power network and trending technologies in the smart grid environment. Based on the instructor's experience and interaction with the students, they enjoyed taking this course and found it useful in understanding the next-generation electric power systems through the up-to-date course content and project assignment.

A student feedback survey was conducted through a web-based course management system, i.e., Blackboard, at the end of the semester to get feedback from the students about the course. The student responses were anonymous. According to the responses, i.e., mean scores of the survey, all students appreciated the course content (with the mean score of 4.67 over 5). They enjoyed the course, and they considered that they learned and benefited from it and appreciated the course content and project assignment. Although the course was offered for the first time in fall 2019, students found the course well structured in terms of exercises, quizzes, and assignments and improved their knowledge of the smart grid concept and emerging technologies. 
The instructor learned several interesting and important lessons from teaching the smart grid course in the fall 2019-2020 semester. The first lesson is about the project assignment and its role on students' motivation and knowledge. Most students indicated that the project assignment is the part of the course they liked the most, and they consider that it helped them to improved their knowledge. For this reason, for the second round of the course, in fall 2020, the instructor gave more opportunities and freedom to students on the selection of the project assignment. However, the quality of research went down in terms of deep analysis. The reason is that students focused on a broad topic instead of a specific topic, for example, renewable energy, as a broad topic versus solar PV as a specific topic. The instructor is planning to change the project assignment strategy in the following semesters by assigning specific topics again to allow students to perform deep research on their project assignment. The second lesson learned is about the course content and students' attention to the specific lectures. Students were more interested in trending technologies, especially renewable energy, EV, and batteries, and asked more questions during those lectures. The instructor plans to extend the course content with additional trending topics, such as machine learning, artificial intelligence, etc., in response to students' interest in more current issues of the field. The third lesson learned is about the handson activities. The course included several hands-on activities for load and energy generation forecasting and anomaly detection cases using machine learning algorithms in fall 2020. However, the students' involvement in these activities was limited. This may be due to running these hands-on activities remotely during the COVID-19 pandemic or to their limited knowledge in machine learning and artificial intelligence. The future delivery of the course will try to include either additional lecture material or additional study material on machine learning basics.

\section{Conclusion}

The paper presents a new course on smart grid technologies offered for the first time for senior undergraduate students in an electrical engineering technology program. The course was offered in hybrid mode, i.e., campus and online students, with WebEx delivery. This paper presents details of both course lectures and project assignments. The course content was developed to include smart grid technologies, applications, and emerging technologies. The main goal was to better prepare EET students for the industry that is changing rapidly due to the trends in the supporting systems that are used in modern Electric Power Systems, Machines and Energy and more workforce that would understand the new technologies, who can replace the aging workforce and fill in the existing gap that exists. The experience of the course in the new format led to the conclusion that the use of project assignments helped students to better understand the four-layer structure of a smart grid, namely power, communication, security, and application. The project assignment proved to be an effective way to assist students in understanding the smart grid concepts, the associated technologies, and their applications. The course will be revised continuously based on student feedback and lessons learned about the content, project assignment, and hands-on activities. 


\section{References}

[1] Yoder, B. L. (2017). Engineering by the Numbers, American Society of Engineering Education, Retrieved on January 1, 2021 from: https://www.asee.org/documents/papersand-publications/publications/college-profiles/2017-Engineering-by-NumbersEngineering-Statistics.pdf

[2] Sen, P. K. (2011, April). Electric power and energy engineering education in USA: A status report, issues and challenges. In 2011 Rural Electric Power Conference (pp. A1-1).

[3] Holland, S. (2020). Power systems engineering is one of primarily subfields in electrical engineering, Electronics Engineering, Retrieved on January 4, 2020 from: https://www.electronicspoint.com/opinion/electrical-and-electronics-engineering-whatsthe-difference

[4] NIST (2018), NIST Smart Grid Conceptual Model, National Institute for Standards and Technology, Retrieved on January 1, 2021 from:

https://www.nist.gov/system/files/documents/2018/11/08/draft_smart_grid_conceptual_m odel update v3.pdf

[5] ABET (2021). Find a Program, the Accreditation Board for Engineering and Technology, Inc., Retrieved on January 7, 2020 from: https://www.abet.org/etac/

[6] Mohan, N. (2012). Electric Power Systems: a first course. John Wiley \& Sons.

[7] Kuzlu, M., Pipattanasomporn, M. and Rahman, S. (2014). Communication network requirements for major smart grid applications in HAN, NAN and WAN. Computer Networks, 67, pp.74-88.

[8] PayScale (2021a). Average Power Engineer Salary, Power Engineer, Job, United States, PayScale.com, Retrieved on January 7, 2021 from https://www.payscale.com/research /US/Job=Power Engineer/Salary

[9] PayScale (2021b). Average Electrical Engineering Technologist Salary, Electrical Engineering Technologist, Job, United States, PayScale.com, Retrieved on January 7, 2021 from https://www.payscale.com/research/US/Job=Electrical_Engineering Technologist/Salary

[10] Bose, A., Fluek, A., Lauby, M., Niebur, D., Randazzo A., Ray, D., Reder, W., Reed, G. F., Sauer, P., Wayno, F. (2009). Preparing the U.S. Foundation for Future Electric Energy Systems: A Strong Power and Energy Engineering Workforce, IEEE Power \& Energy Society, April, 2009.

[11] Reed, G. F., Stanchina, W. E. (2010_Smart grid education models for modern electric power system engineering curriculum," IEEE PES General Meeting, Providence, RI, 2010, pp. 1-5, doi: 10.1109/PES.2010.5589617.

[12] Hosseinzadeh, N., \& Hesamzadeh, M. R. (2012). Application of project-based learning (PBL) to the teaching of electrical power systems engineering. IEEE Transactions on Education, 55(4), 495-501.

[13] Reed, G.F. (2008). Two Solutions to Aging Workforce Issues (Pitt Power \& Energy Initiative and KEMA Operations \& Planning Knowledge Tools), P Power Engineering Magazine, Vol. 112, No. 8, August 2008.

[14] Heydt, G. T., Vittal, V. (2003). Feeding our profession [power engineering education], IEEE Power and Energy Magazine, vol. 1, no. 1, pp. 38-45, Jan.-Feb. 2003.

[15] Kuzle, I., Havelka, J., Pandžić, H., \& Capuder, T. (2014). Hands-on laboratory course for future power system experts. IEEE Transactions on Power Systems, 29(4), 1963-1971. 